\title{
Anabases
}

ANABASES Traditions et réceptions de l'Antiquité

16 | 2012

Varia

\section{Francesco PRONTERA, Geografia e storia nella Grecia antica}

\section{Germaine Aujac}

\section{OpenEdition}

Journals

Édition électronique

URL : http://journals.openedition.org/anabases/4039

DOI : $10.4000 /$ anabases.4039

ISSN : 2256-9421

\section{Éditeur}

E.R.A.S.M.E.

\section{Édition imprimée}

Date de publication : 1 octobre 2012

Pagination : 325-327

ISSN : 1774-4296

\section{Référence électronique}

Germaine Aujac, "Francesco prontera, Geografia e storia nella Grecia antica », Anabases [En ligne], 16 | 2012, mis en ligne le 01 octobre 2012, consulté le 22 septembre 2020. URL : http://

journals.openedition.org/anabases/4039; DOI : https://doi.org/10.4000/anabases.4039

Ce document a été généré automatiquement le 22 septembre 2020.

(c) Anabases 


\title{
Francesco PRONTERA, Geografia e storia nella Grecia antica
}

\author{
Germaine Aujac
}

\section{RÉFÉRENCE}

Francesco PRONTERA, Geografia e storia nella Grecia antica, Firenze, Leo S. Olschki Editore, 2011, 267 p. + IV p.

28 euros / ISBN 9788822260857.

1 C'est un recueil d'articles parus dans diverses revues entre 1993 et 2010 que Francesco Prontera nous présente dans cet important volume, au titre évocateur. Spécialiste bien connu de la géographie antique, F. P. a toujours insisté sur le rôle déterminant joué par le contexte historique dans les progrès de la connaissance du monde habité et, partant, de sa représentation visuelle. Il nous donne ainsi une vision unitaire de problèmes qui touchent soit à l'histoire et à l'historiographie antiques soit à la géographie. D'où la répartition des articles sous deux rubriques : textes et cartes.

2 Soulignant la place exorbitante réservée à Homère dans la Géographie de Strabon, F. P. montre, dans le premier de ces articles, Sull'Esegesi ellenistica della geografia omerica (1993, p.3-14), la persistante influence d'Homère tout au long de la période hellénistique, à travers son imitateur Apollonios de Rhodes et son pourfendeur Ératosthène, et ce jusqu'au siècle d'Auguste.

3 Les Guerres Médiques furent à l'origine de la conscience nationale grecque, développée par les grands rassemblements ethniques que constituaient les fêtes panhelléniques; très tôt apparut le désir de représenter par des schémas géométriques l'espace occupé par les hommes (Identita etnica, confini e frontiere nel mondo greco, p. 15-28).

4 La présence de l'Italie dans le monde habité connu des Grecs (p. 29-43), la description de l'Asie Mineure avec ses divers développements dans la Géographie de Strabon (p. 45-61), l'importance reconnue à la Perse par Hécatée de Milet ainsi que dans la carte 
évoquée par Hérodote (p.63-72), sont autant de vues originales qui offrent des perspectives parfois inattendues et toujours pertinentes.

Quant à la géographie de l'historien Polybe, elle se situerait entre tradition et innovation. Moins progressiste, parce que moins scientifique, qu'Ératosthène, Polybe se distingue par l'attention portée à la géographie régionale (p.73-80). Mais la représentation mythique a aussi sa place dans le développement de la géographie grecque : les diverses hypothèses sur l'itinéraire suivi par Ulysse, ou sur le trajet de retour des Argonautes ont élargi le champ des connaissances géographiques (p. 81-94). Des notes sur le lexique de la cartographie antique, portant sur la distinction précisée par Ptolémée entre la " géographie » et la « chorographie » (p. 95-104), le rappel du rôle de Marcien d'Héraclée, grâce auquel des auteurs comme Artémidore ou Ménippe de Pergame sont mieux connus (p. 105-112), ainsi que des notes sur la géopolitique au v siècle, embrassant l'Asie, la Grèce, la Sicile et l'Italie (p.113-128) complètent cette partie consacrée aux textes.

6 Sous la rubrique "cartes ", sont groupés des articles mettant en relief l'influence des relations maritimes sur la représentation cartographique. Le premier de la série, Geografia nautica e rappresentazione litoranea della magna Grecia (p. 129-147), montre que la colonisation grecque, avec la création de nouvelles cités le long des côtes de la Méditerranée et de la mer Noire, a fait prévaloir une perspective maritime dans la description des pays du monde habité ; « c'est la mer au premier chef qui décrit la terre et lui donne sa forme ", assurait Strabon dans le chapitre consacré à l'établissement de la carte (II, 5, 17). Ce sont ces bases empiriques de la cartographie grecque, fondées essentiellement sur des données maritimes, que détaille F. P. avec grande pertinence (p. 149-165). Mais sur les mappemondes grecques, où se trouvait le centre et quel était le tracé de la périphérie ? Aux cartes circulaires des Ioniens, centrées sur Delphes ou la mer Égée, mettant face à face la Grèce et l'Asie mineure, a succédé la carte d'Ératosthène largement développée autour de deux axes de coordonnées qui, se coupant à Rhodes, faisaient de cette île le centre géographique de la carte (p. 167-182). Deux exemples illustrent l'utilisation des données empiriques en matière de cartographie. La péninsule Ibérique, dont la position et le tracé étaient très incertains pour Aristote, bénéficia des récits de Pythéas le marin, qui en fit le tour lors de son fameux périple en direction du Nord de l'Europe, mais aussi de l'expérience des armées carthaginoises et romaines lors de la deuxième guerre Punique; Ératosthène, puis Ptolémée purent en tracer des schémas plus ou moins vraisemblables (p. 183-196). Quant à l'Asie mineure, la description qu'en donne Strabon, bien que fondée pour l'essentiel sur la carte d'Ératosthène, n'en offre pas moins un tableau pittoresque riche des souvenirs d'un enfant du pays, dont la famille fut très impliquée dans la gestion et la politique du royaume du Pont ; les guerres de Mithridate contribuèrent à mieux faire connaître cette péninsule asiatique (p.197-223). Le désir des Grecs d'embrasser, au moins par la pensée, l'ensemble du monde habité, s'explique par des présupposés historiques : l'expérience coloniale de l'époque archaïque et, plus tard, l'unification de l'Asie sous la domination perse. Hécatée de Milet avait inauguré, dans son Tour de la terre, une description ordonnée des peuples et des pays du monde habité qui perdura jusqu'à Strabon. «Il est bien clair que dans l'historiographie antique (surtout grecque), le récit des événements s'accompagne de la description ethnico-géographique des pays qui constituent le théatre des actions humaines ", déclare F. P., qui montre dans la Géographie de Strabon la part réservée à l'ethnographie (p. 225-238). Une étude sur la 
Sicile (p. 239-253) termine cette série consacrée aux cartes. Inutile d'ajouter que tous ces articles sont brillamment illustrés par des schémas divers.

7 En manière de conclusion (et c'est aussi sa production la plus récente, 2010), F. P. résume son propos dans Carta e testo nella geografia antica (p. 255-263). Rappelant que nous ne possédons plus aucun document original sur la cartographie antique, il souligne l'importance des textes qui nous offrent la description de tout ou partie du monde habité, sans pour autant en conclure que leurs auteurs avaient sous les yeux une carte qui leur fournissait l'appui nécessaire. Pourtant la présentation géométrique de la carte d'Ératosthène, puis l'influence, restée trop mystérieuse, de Poseidonios, enfin la somme représentée par la Géographie de Strabon montrent la présence et l'évolution de la pratique des cartes bien avant qu'intervienne Ptolémée.

C'est donc un ouvrage riche en vues pertinentes sur le développement des sciences connexes que sont la géographie et la cartographie, et sur leurs rapports avec le contexte historique, que nous offre ici ce spécialiste reconnu de l'histoire de la géographie.

\section{AUTEURS}

\section{GERMAINE AUJAC}

Université de Toulouse (UTM) aujac.germaine@wanadoo.fr 